\title{
Antarctic environmental planning and management: conclusions from Casey, Australian Antarctic Territory
}

\author{
Lorne K. Kriwoken
}

Centre for Environmental Studies, University of Tasmania, Hobart, Tasmania, Australia

Received January 1989

ABSTRACT. The Antarctic environment has undergone significant local environmental damage and degradation, with nations rebuilding, expanding, or developing stations and bases. The Australian Antarctic Division's ten-year (1985-95) A \$76.704 million programme of rebuilding and expanding stations in Australian Antarctic Territory is representative of a continent-wide increase in station numbers and impact, increasing station size, human numbers, lengths of roads, buildings, waste material production, and energy requirements. Environmental planning and impact assessment have not been incorporated in official decision-making; human activities at Australian Antarctic Territory stations had serious impacts on the limited ice-free land and local flora and fauna. Casey, a re-developed station, is examined with reference to environmental planning and management under Antarctic Treaty obligations and recent Australian environmental legislation. Recommendations include the setting up of an Australian Antarctic Resources Committee responsible inter alia for environmental planning and management, including regional and station management plans and cumulative and environmental impact assessment for all Antfrctic operations.

\section{Contents}

Introduction

Growth of human impact

Planning and management legislation

Impacts at the Wilkes/Casey site

Recommendations

An Australian Antarctic Resources Committee

Summary and conclusions

Acknowledgements, references

\section{Introduction}

Antarctica's very limited ice-free terrestrial environment is subject to increasing human impact as nations rebuild or expand over-wintering stations and summer bases. All nations acceding to the Antarctic Treaty, signed in 1959 . were required under Article IX(2) to conduct research activity "including the establishment of stations or the dispatch of a scientific expedition', in order to become an Antarctic Treaty Consultative Party (ATCP). Although this requirement was removed in 1977, new parties have continued to construct stations. Because the Antarctic Treaty does not provide prescriptive advice on the siting of stations, increased numbers of ATCPs and the number of states acceding to the Antarctic Treaty since 1977 have exacerbated environmental impact with the expansion of facilities.

Currently 22 nations operate 44 stations and about 45 summer bases in the Antarctic Treaty area. Summer and winter populations are in the order of 2700 and 800 respectively. Some are concentrated in small areas (notably King George Island and Ross Island). Increased human activity associated with Antarctic stations and bases has resulted in significant localized environmental damage and degradation to the terrestrial environment (Bonner 1984; Benninghoff and Bonner 1985).
Australian Antarctic Territory (AAT) has eight stations and 12 bases (1988) of which three stations and two bases are operated by Australia, the rest by USSR. The Australian ten-year programme (1985-95) of rebuilding and expanding its three permanent stations Casey, Mawson and Davis, on a budget of A\$76.704 million (Australia 1988), involves a growing environmental impact. The programme will increase the size of stations and the number of buildings and personnel, the length and complexity of roads, and the amounts of waste material and consumed energy.

This article examines a conspicuous lack of environmental planning and management (EPM) at Casey, and recommends EPM in all future Australian Antarctic operations, under an independent Australian Antarctic Resources Committee with responsibility for management planning and environmental and cumulative impact assessments.

\section{Growth of human impact}

Human activity on continental Antarctica began in 1898 when Borchgrevink first wintered on land. Within the next 60 years exploration was limited to small parties with concentrated facilities. Station locations were mostly sites accessible from the sea and free from summer snow. On a continental scale the impact of these expeditions was minimal. Within this early period only two stations were built in AAT, for Mawson's Australasian Antarctic Expedition (Chester 1986) at Cape Denison in 1911, and Mawson, the first ANARE station, in Holme Bay in 1954 (Law 1983).

From the International Geophysical Year (IGY) of 1958-59 the numbers, size and impact of Antarctic stations increased substantially. For IGY some 50 were established continent-wide (Benninghoff and Bonner 


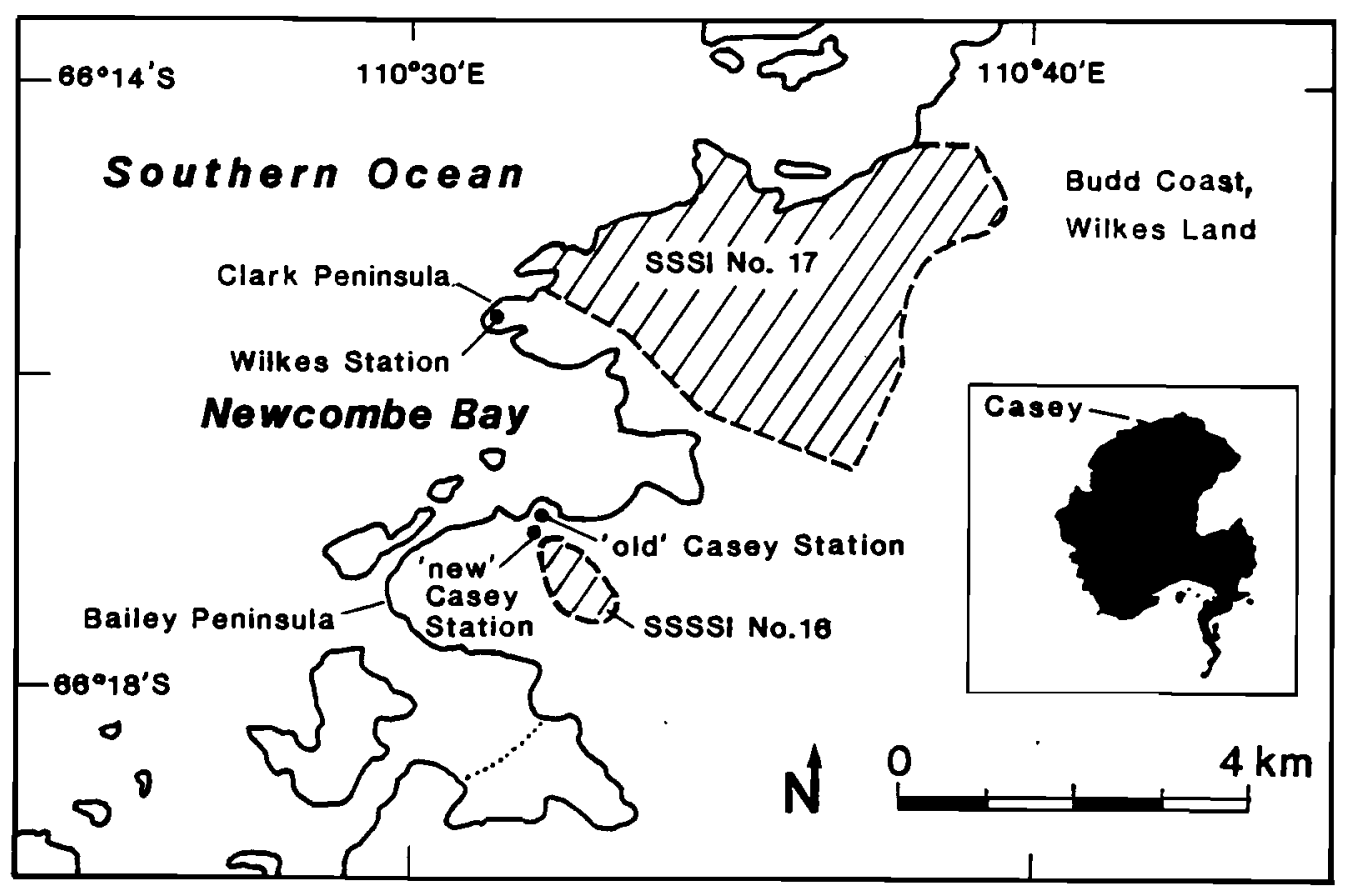

Fig. 1. Location map.

1985: 16): within AAT, Australia, USSR and USA respectively established Davis, Mimy and Wilkes on the coast, and several smaller field stations, and USSR established Vostok inland.

After IGY several stations were maintained in use. Over the years the populations of surviving stations and their successors have tended to grow, their facilities and infrastructure expanded, and their impact on the ice-free terrestrial environment increased. During the late $1960 \mathrm{~s}$ and ' 70 s temporary stations of IGY vintage became structurally unsound, and permanent stations involving heavy construction materials, and requiring elaborate construction machinery and facilities, were built to replace them. Some of these are again due for replacement. Succession is illustrated in the Newcombe Bay region, Wilkes Land. Wilkes, on Clark Peninsula, was built of temporary materials for IGY by the US and abandoned after a year's use. It was used by Australia for four years while a new station, Casey, was being built on nearby Bailey Peninsula (Fig. 1 ), and finally abandoned in 1969 . 'Old' Casey was recently (1986-87) replaced by a new building complex on a third site in the area (see below).

From about 1977 there was a significant increase in the number of states acceding to the Antarctic Treaty, including several with ATCP status. In AAT the scale of Soviet operations exceeded that of Australia. On Antarctic Peninsula Argentine and Chilean parties included families. Stations became polar townships with associated infrastructure, some including such cost-recovery activities as tourism (Headland and Keage 1985).

From the 1970s onward environmental planning and impact legislation, including land and water resources planning, pollution control, and environmental impact assessment came to be accepted in Australia (Buckley 1988: 206; Bates 1983: 8). An Australian Environment Council was created to co-ordinate federal and state envi- ronmental matters. The state of Victoria introduced the Environment Protection Act in 1970 and New South Wales introduced its Planning and Environment Commission Act in 1974 (Bates 1983). In 1974 the federal government introduced the Environment Protection (Impact of Proposals) Act, which provides for the environmental impact of proposed Australian activities in the Antarctic, and the Australian National Parks and Wildlife Service was created in 1975 to establish and manage parks and reserves over land and sea areas.

The replacement of Casey is part of Australia'scurrent rebuilding programme in which its three permanent stations Casey, Davis and Mawson, will all be replaced. The Department of Housing and Construction (DHC), acting as client to the Australian Antarctic Division (AAD), began work in 1979-80. Old Casey, located on a rock peninsula and separated from the mainland by Thala Valley, consists of buildings on an elevated scaffolding structure set across the prevailing wind (Figs. 2 and 3 ). Subject to continual snow drift and stress failures, the buildings have suffered extensive structural deterioration. New Casey, $0.7 \mathrm{~km}$ from the old, was built mainly in 1986-87. The old station is scheduled for eventual removal.

Areas adjacent to Casey with rich and diverse colonies of moss, lichen, and algae were identified in the early 1960s but never designated as protected areas. Federal environment legislation specifically requiring impact assessment existed before the rebuilding programme began. Yet the new station was built adjacent to Site of Special Scientific Interest (SSSI) No 16 (Fig. 1). Application of established principles of EPM was, and continues to be, ignored by DHC and AAD. The result has been to degrade severely the terrestrial environment surrounding both old and new Casey stations, and the adoption of misguided and inadequate management practices. 


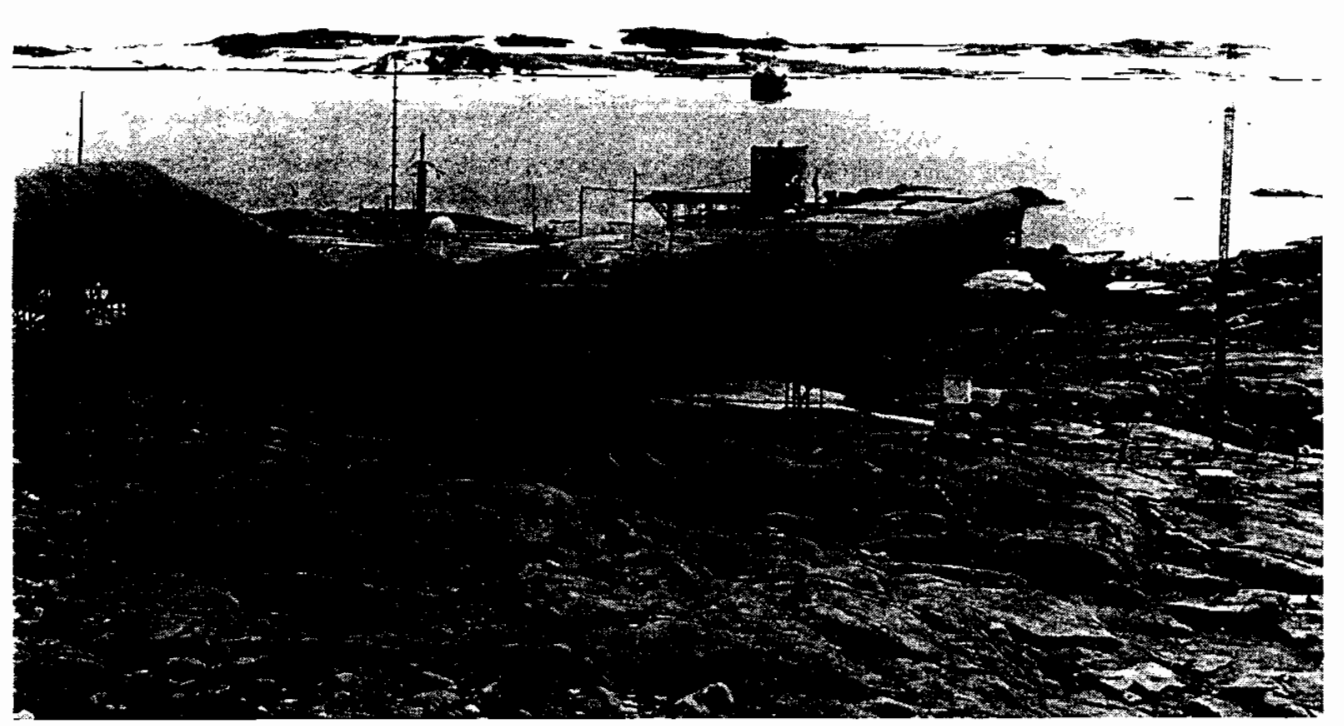

Fig. 2. 'Old' Casey in foreground: looking north across Newcombe Bay to Clark Peninsula and the site of Wilkes Station.

\section{Planning and management legislation}

\section{Antarctic Treaty and related recommendations}

International obligations for protection of the Antarctic environment derive from the Antarctic Treaty and subsequent measures formulated and agreed by the ATCPs. The Agreed Measures for the Conservation of Antarctic Fauna and Flora 1964 provide for the conservation of flora and fauna and the protection of the environment. The preamble to the Agreed Measures considers the whole of the treaty area to be a 'Special Conservation Area', and the measures provide for two categories of protected areas, Specially Protected Areas (SPAs) and Sites of Special Scientific Interest (SSSIs).

However, Article VII (Agreed measures, Harmful Interference) permits the disturbance of a protected area to provide for the establishment, supply and operation of stations. As a result there are instances where stations, huts and helipads have been established in protected areas, for example on King George Island, South Shetland Islands (Headland and Keage 1985). There is strong evidence from other sources that these sites are accorded insufficient environmental protection (Kriwoken and Keage 1989).

Station activities were addressed at the Eighth Antarctic Treaty Consultative Meeting of 1975, where a 'code of conduct' was promulgated for nations to cover the disposal of wastes by expeditions and stations. The code recommends inter alia that liquid waste should be macerated and flushed to sea, non-combustibles dumped in the sea and combustibles burnt, but batteries, all plastics, rubber, and radioisotopes should be removed from the Treaty area (Bonner 1984: 839). The twelfth consultative meeting in 1983 recommended (XII-3) that ATCPs undertake EIAs before constructing or expanding stations and when conducting scientific studies. However, nowhere in the Antarctic Treaty system are there guidelines on the siting of permanent stations, summer bases, or research facilities with respect to environmentally sensitive areas. Specific management plans designating the size and design of the bases and the extent and operating criteria of station activities in a region are not required for scrutiny. There is no comprehensive view of future station development and no requirement for EIAs or EPM.

Australian legislation and administrative responses Under the Agreed Measures and the Antarctic Treaty (Environment Protection) Act 1980 arising from them, Australia declared two SSSIs in the Newcombe Bay region (Fig. 1). Bailey Peninsula SSSI No 16, immediately adjacent to new Casey, protects a diverse assemblage of moss and lichen communities, and was designated inter alia as a site to assess human impact (Plate 3). Clark Peninsula SSSI No 17, east of Wilkes, contains moss and lichen communities used as control sites from which baseline data are collected to enable changes adjacent to Casey to be monitored. SSSI No. 16 has been severely degraded by operations associated with the Casey rebuilding programme.

The Environment Protection (Impact of Proposals) Act 1974-75 requires consideration of environmental impact of proposed Australian activities in Antarctica. The Act is intended to ensure that matters affecting the environment, to a significant extent, are taken into account in all plans and actions of federal agencies, and provides for four levels of assessment: initial evaluation of the proposal; preparation of a Public Environment Report (PER); preparation of an Environmental Impact Statement (EIS); and an examination by a Commission of Inquiry.

However, no Australian Antarctic re-supply operations, construction and expansion of stations or scientific programmes have ever been subject to a PER, EIS, or a 


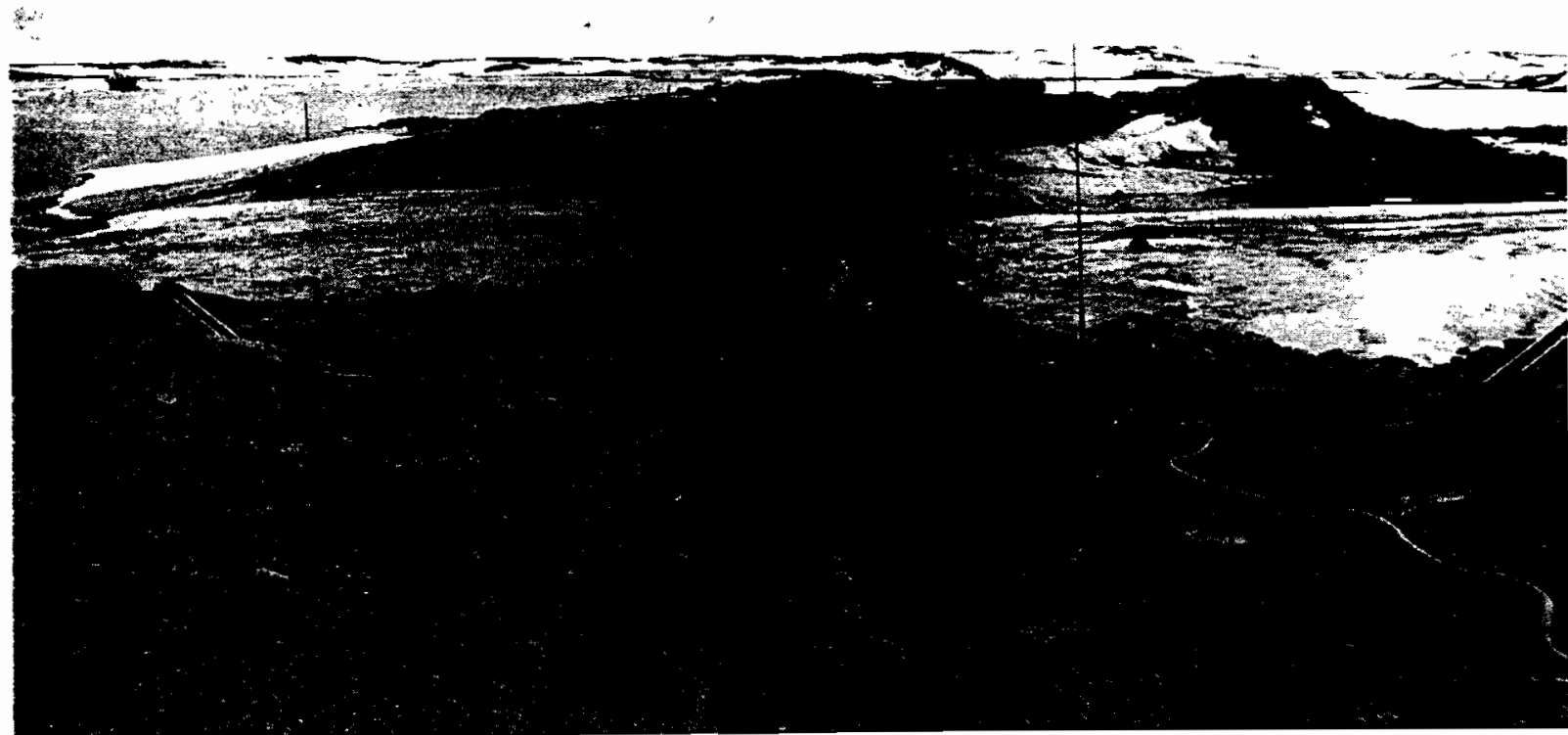

Fig. 3. New road connecting 'old' Casey Station to the mainland across Thala Valley.

Commission of Inquiry. The initial evaluation of the rebuilding programme required $\mathrm{AAD}$ to lodge a notice of intention to the then Department of Science and the Environment (DSE) in 1980. Further clarification was provided by AAD: '[t]he impact upon the environment caused by the proposed rebuilding of Australian Antarctic stations will be confined to existing station areas and is, therefore, considered not to be a serious imposition' (Australia 1981a). However, the same report identified two significant impacts:

* permanent alteration and contamination of soils in icefree areas by physical means such as vehicular traffic, aircraft landings, etc. and the introduction of exotic food sources; and

* alteration of the physical components of the ecosystem so as to spoil their global benchmarks or as data for such processes as climatological changes and longer term solar activity and its changes.

DSE concluded that ' ... it should not be necessary to recommend to the Minister that an environmental impact statement be prepared' (Australia 1981b: 541). Thus because the Act is discretionary rather than mandatory, rebuilding programme activities have never been subject to a PER or an EIS, even when permanent alteration and contamination of soils and alteration of the physical components of the ecosystem was acknowledged. The environmental impact predicted to be 'confined to exisiting station areas' was never defined in areal terms, nor were the boundaries of the station area mapped.

At an operational level, AAD, with a $1987-88$ budget of $A \$ 49.248$ million (ANARE News 1987: 14) within the enlarged Department of Arts, Science, the Environment, Tourism and Territories (DASETT), has an Environment Committee in which environmental policy is interpreted and management implemented. The Committee is an advisory body to the Board of Management of AAI. providing advice on environmental aspects of Australian National Antarctic Research Expedition (ANARE) activities and ways in which impact on the environment can be minimized, and general Antarctic matters (Antarctic Science Advisory Committee 1986: 58). It consists of representatives from AAD, DHC, and DASETT.

The Committee at present includes no full-time environmental planner responsible for co-ordinating activities, and it has no function in operational or forward planning activities or policy initiatives. From 1983 to 1990 the Committee has never recommended that any Australian Antarctic activity be subject to a PER or EIS. It seems that, with respect to on-going $A A D$ projects, the Committee has actually operated to divert environmental review from those outside. In 1982 it voluntarily disbanded for twelve months because its recommendations were totally ignored by AAD management, which was not obliged to address them. This represented a critical time when forward planning and EIA were urgently required, and the Committee had its highest potential value. Currently (1990) only four of its 13 members have expertise in biology or environmental studies; the rest are ex officio with no special environmental planning skills.

It is not surprising, therefore, that the need for EPM in station activities has been continually overlooked by the Committee. It would appear that the AAD has neither the expertise nor the inclination for such activities, with the result that operational and development concerns, including the rebuilding programme, continue to enjoy priority over environmental planning and management.

\section{Impacts at the Wilkes/Casey site}

Despite the wording of the 1980 AAD report, impact upon the environment caused by the rebuilding of Australian 


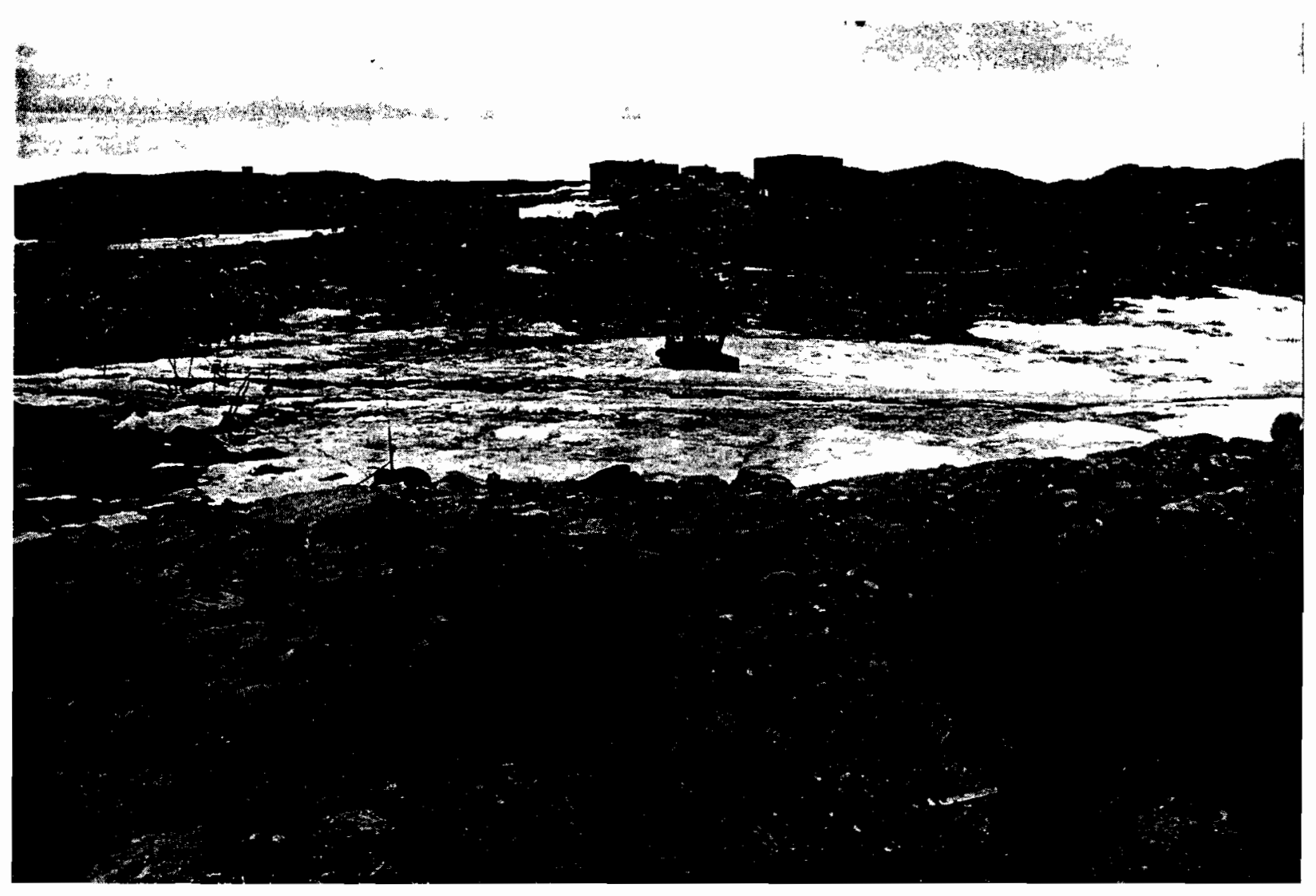

Fig. 4. Northwest corner of SSSI No. 16, immediately adjacent to 'new' Casey Station.

Antarctic stations is not confined to 'existing station areas'. The new Casey occupies a new site $0.7 \mathrm{~km}$ from the old. Appropriate recognition of the sensitivity of the icefree land, and particularly the nearby protected area, was not given prior to station expansion. The arrival of engineers and construction crews brought many more people into the area, infrastructure and facilities expanded, and impact on the whole of the surrounding ice-free area increased significantly.

The extended Casey area has become a high-density settlement with large energy consumption and waste disposal requirements. The impact of the rebuilding programme is well documented: associated air pollution is having short-term and long-term environmental impact on the adjacent terrestrial ecology (Lewis-Smith 1986). SSSI No 16 , containing rich lichen and moss communities and supporting long-term taxonomic, ecological, and physiological research, has been seriously degraded. At the 1985 Senate Standing Committee on National Resources evidence was received that:

... a lake beside Casey dramatically altered as a result of ground in the catchment being disturbed, resulting in glacier flour entering the lake; cement dust broadcast extensively; plastic cement bags disposed of by throwing them in the sea, only to re-appear on the shores; morainic rock at Mawson being used to feed rock-crushers for concrete production; various engineering manipulations to provide adequate water supply, particularly to meet the heavy demands of the water-flush toilet system being introduced... (Australia 1985: 75).

The three periods of expansion have cumulatively degraded the environment of Bailey and Clark peninsulas. Neither of the old stations has been cleared, so impacts have therefore spread over an unnecessarily large area; in just over 30 years 9.5 ha of the ice-free land surrounding Newcombe Bay have been irreversibly changed (Table 1). In addition, there are three field huts within $22 \mathrm{~km}$ of Casey.

The length and complexity of roads, an excellent index of clustering of station facilities, has increased ten-fold (Table 1). Approximately $2 \mathrm{~km}$ of road now service a widely dispersed station area, with associated increases in fuel consumption, dust, and congestion. Fuel consumption for station operation has increased over four-fold (Table 1). The new road on the causeway linking old and new Casey has been subject to an increased level of maintenance activity. Until the old station is closed and removed, fuel use will remain high. The AAD 'notice of intention' made no mention of the problems of a widely dispersed station and increased fuel consumption.

Increased station population has not brought about a proportional increase in scientific personnel. The winter population has not changed greatly in 30 years, but summer population has almost doubled (Table 1): most visits are occurring when the ice-free terrestrial ecosystem is most vulnerable to impact. The AAD 'notice of intention' 


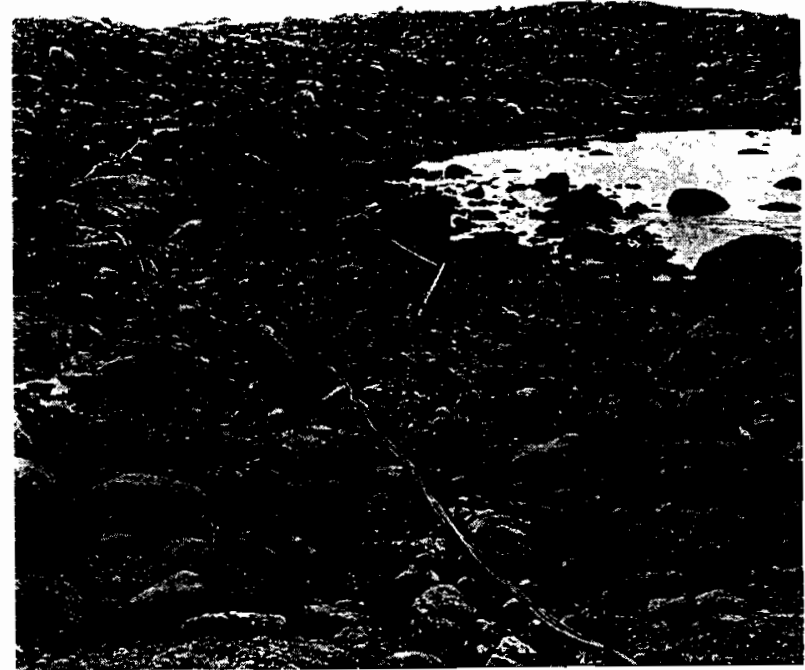

Fig. 5. Cables servicing a radio transmitter in SSSI No. 16 laid directly on protected moss beds.

did not cite any increase in numbers or associated impact on the terrestrial ecosystem.

Scientific commitment to Casey seems to be eroding. The glaciology programme has stopped, with only a summer drilling programme planned. In 1988-89 one biologist over-wintered. If stations are justified for their scientific role, Casey is almost solely justified by its terrestrial biology programme. Critical to this research is the adjacent SSSI, the very area that the rebuilding programme placed in jeopardy. Ecosystems close to new Casey are fragile, with small capacity to absorb change, including fellfield communities of lichen and mosses (Benninghoff and Bonner 1985). Vulnerability of the moss beds was recognized in the 'notice of intention', and one site alternative was rejected because of its potential impact (Australia 1981b: 580). However, new Casey stands on the northern edge of the most sensitive area. The question of minimizing its impact by locating it on the site of old Casey does not seem to have warranted serious consideration.

Though moss beds immediately southeast of new Casey received their SSSI status in 1985, both old and new Casey operations had already adversely affected the area. Concrete mixing sent a plume of alkaline cement dust from the batching plant, often covering the adjacent moss beds and contaminating the soil (Lewis-Smith 1986), and a twoha moss bed adjacent to new Casey and outside the SSSI was almost killed by pollution (ibid.). SSSI status has not ensured adequate protection from station activity: close proximity, though ideal for research, maximizes chances of disturbance. Cables servicing the radio transmitter at the south end of the protected area have been laid directly on the moss beds (Fig. 5) and, with the cycle of freeze and thaw, have become embedded. These are the very moss beds the SSSI was designated to protect, and an area critical to the terrestrial biology programme which largely justified Casey's existence.

Wilkes, on a 1.5 ha site, consists of dilapidated wood and canvas buildings, abandoned heavy equipment, fuel drums, wood, wire, cable, and plastic (Fig. 6). The site cannot readily be cleaned up by Casey personnel: rehabilitation will require a massive collaborative effort, presumably between Australia and the United States, with removal of dangerous and environmentally deleterious substances given high priority. As a former IGY station Wilkes may have some historic value: there could be a case for restoring one or more buildings of historic importance and developing interpretative and educational material for future visitors.

Waste materials have been generated from the rebuilding programme and the old Casey site, and a formal comprehensive waste management programme is needed to deal with it. Old Casey, like Wilkes, may include representative buildings of historic importance that should be preserved. Berms surrounding bulk fuel storage tanks are needed to contain fuel in the event of a leakage or spillage, and careful monitoring is needed during fuel transfer operations.

\section{Recommendations}

Clearly, neither international nor national legislation currently provide adequate management guidance for station activities in Antarctica. Measures under the Treaty are largely discretionary, prescribing largely-meaningless conservation measures for Antarctica and failing to support them in practical ways. National legislation, which might be expected to make up for these deficiencies, does not do so. Regional zoning and station management plans are not required: discretionary legislation allows EIAs and similar planning measures to be ignored by responsible authorities. The AAD has no environmental planner. Australian Antarctic Territory is therefore accorded a much lower level of environmental protection and management than is presently found in continental Australia.

Antarctic operators such as AAD are often simultaneously the developer supporting re-supply and rebuilding activities and the environmental watchdog enforcing

Table 1 - Environmental impacts of Wilkes, 'Old' Casey, and 'New' Casey stations. " Includes remote radio communications facilities. "* Index of clustering of station facilities. "** Includes only power station fuel consumption; fuel used for vehicles and field work would be extra.

$\begin{array}{lccccccc} & \begin{array}{c}\text { Winter } \\ \text { population }\end{array} & \begin{array}{c}\text { summer } \\ \text { population }\end{array} & \begin{array}{c}\text { area* } \\ \text { (ha) }\end{array} & \begin{array}{c}\text { length of } \\ \text { roads** (m) }\end{array} & \begin{array}{c}\text { fuel usage } \\ (1 \times 1000)^{* * *}\end{array} & \begin{array}{c}\text { construction } \\ \text { time (years) }\end{array} & \begin{array}{c}\text { operating } \\ \text { period }\end{array} \\ \text { Wilkes } & 18-25 & 45 & 1.5 & 200 & <200 & 0.5 & 1956-69 \\ \text { 'Old' Casey } & 22-28 & 45 & 2 & 400 & \sim 410 & 4 & 1969-88 \\ \text { 'New' Casey } & 25-35 & 80 & 6 & 2000 & \sim 700 & 8+ & 1988-?\end{array}$




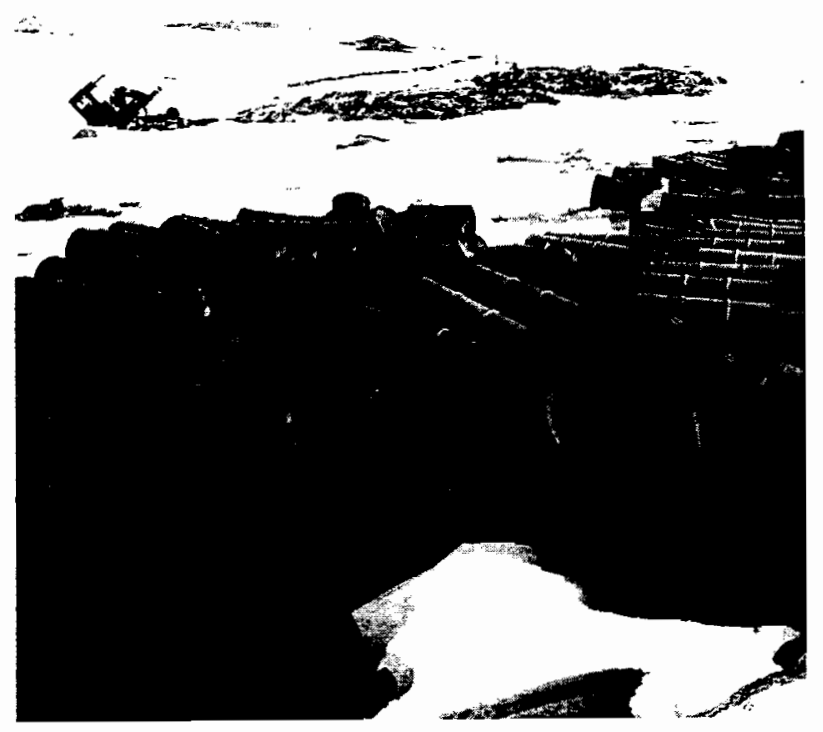

Fig. 6. Abandoned fuel drums and heavy equipment, Wilkes Station.

environmental policy, allowing development and operational priorities to take precedence over environmental planning and management. Environmental planners do not regularly visit and inspect stations, examining all aspects of operations over extended periods of time. Present environmental reviews are conducted on a short-term basis as opportunity presents, and do not allow for longterm studies. The responsibility inherent in Australia's claim to $42 \%$ of Antarctica is largely ignored.

\section{Regional plans}

Regional plans must be developed for all station areas, to protect terrestrial and marine environments. Spatial separation or zoning should be adopted as the primary means of regulating incompatible uses, so that sensitive areas can be protected from damaging activities. Zoning in the regional land use context includes the generation of zoning plans and zoning classifications. The former involves setting up a management plan for a geographic region where certain activities are permitted. Regional plans should address the cumulative impact of human activity on regional dependent and related ecosystems, with research programmes to measure cumulative effects assessment (Sontagg and others 1988) incorporated. Flexible regional environmental databases or geographic information systems (Buckley 1988) should become management tools.

Regional plans must recognize the importance of Antarctic cultural heritage, for example in the Newcombe Bay region where three generations of Antarctic stations stand side-by-side. Australia has a unique opportunity to lead in this direction by instigating projects that document Wilkes and old Casey, and promote guidelines to manage these historic sites and heritage resources. These projects should be included in the planning and budgeting of AAD.

\section{Management plans}

A second research priority should be the development of management plans for all AAT stations, covering all human activities in or associated with the station, that recognizes the sensitivity of the surrounding terrestrial and marine ecosystem. Kriwoken and Keage (1989) suggest that station boundaries and plans of management need to be implemented to establish management responsibility for station operations. As suggested by Benninghoff and Bonner (1985), these require EIAs to serve as baselines for future human impact assessment.

EIAs should be mandatory for all rebuilding programmes in order that public review and comment can be solicited. An ecological framework for EIA developed by Beanlands and Duinker (1983), using the concept of Valued Ecosystem Components (VEC), should be adopted. An environmental assessment and management simulation model based on Holling (1978) has been suggested as a possible means to identify the optimum (environmental) station size (Keage and Quilty 1988: 10). This is a critical component of the plan because boundaries that limit the areal extent of station expansion delineate and zone human activity to minimize impact on the surrounding ice-free land. Station size must be considered as a function of the host environment and in proportion to station function. Geographic and population criteria alone are not adequate.

Antarctic stations now cover greater areas as buildings are widely separated and continue to increase in number. The volume of waste material and energy requirements increase as stations become townships rather than small scientific bases. Motivation for these stations as research centres must be questioned. The settlement history of Wilkes Land, for example, does not exemplify an expanding scientific commitment proportional to station expansion. Station expansion reflects increasing political, not scientific, commitment to AAT.

In the instance of Casey, management plans should include restrictions on type, extent, and use of vehicles. Use of vehicles outside the station area should be strictly prohibited: vehicles should not be allowed off roads within the station area, and no vehicles should be allowed within the local SSSIs. The close proximity of SSSI No 16 requires the special designation of a buffer zone surrounding the protected area. A review of the plan must be accepted as a feature of the planning process to enable policy adaptation to take place as necessary to ensure that management objectives are attainable.

\section{An Australian Antarctic Resources Committee}

Australia urgently requires an independent body responsible for environmental planning and management in all aspects of its Antarctic operations. The Canadian Arctic Resources Committee (CARC) is an appropriate model, incorporating a broad spectrum of planning and management. CARC is an independent analyst with wide ranging agenda including environmentally sensitive areas, cultural heritage, native land claims, and oil and gas policy. With a full-time staff of six and publicly funded, CARC includes a multidisciplinary Working Committee with an 
agenda set by its members. Experts from various disciplines are encouraged to contribute.

An independent Australian Antarctic Resources Committee (AARC) would have equally wide responsibilities analyzing all Australian Antarctic operations. An AARC Working Committee would be appointed to provide prescriptive advice on long-term issues, replacing AAD's inadequate reactive Environment Committee. Advice would include inter alia assistance in station and base layout and design, recommending projects for EIA and monitoring, promoting protected area designations and design, and suggesting scientific research. The Working Committee could exchange its reports via the Scientific Committee on Antarctic Research (SCAR) Working Group on Biology and its Conservation Sub-Committee. It could provide general advice on scientific matters related to EIA to agencies administering EIA procedures, and promote the formal recognition of monitoring as an integral component of the assessment process. Contributions from research scientists and experts in EIA could be solicited, and the importance of co-operative research and study programmes acknowledged and supported.

\section{Summary and conclusions}

In summary, the following recommendations are intended to stimulate further government thinking on Australia's role in Antarctica:

* The appointment of an independent Australian Antarctic Resources Council (AARC), with responsibilities for environmental planning and management in all aspects of Australian Antarctic Territory operations, is strongly recommended.

* Regional plans are needed, addressing the cumulative impact of human activity on regional dependent and related ecosystems, with the aim of conserving the terrestrial and marine environment.

* Management plans including EIAs are needed for all Australian Antarctic Territory stations. They should cover all human activities in or associated with the station, and recognize the sensitivity of the surrounding terrestrial and marine ecosystem.

\section{Acknowledgements}

The author is a Post-doctoral Research Fellow at the Centre for Environmental Studies, University of Tasmania. Antarctic research is supported by grants from the Australian Research Council, the Antarctic Science Advisory Committee (Australia), the University of Tasmania and the Trans-Antarctic Association (United Kingdom). I thank Peter Keage and Peter Hay for comments and advice on this paper and Airlie Alam for drafting Fig. 1.

\section{References}

ANARE News. 1987. Antarctic budget 1987/88. Anare News 52 (December): 14.

Antarctic Science Advisory Committee. 1986. Overall priorities in Australian Antarctic Science. Canberra, Department of Science (Second Occasional Paper).
Australia. 1981a. Background paper on the Antarctic environment with particular reference to the proposed rebuilding of Australian Antarctic stations. Canberra, Department of Housing and Department of Science and Technology.

Australia. 1981b. Minutes of evidence relating to redevelopment of Australian Antarctic bases, Part I and II. Partiamentary Standing Committes on Public Works. Canberra, Parliament of the Commonwealth of Australia.

Australia. 1985. The natural resources of the Australian Antarctic Territory. Senate Standing Committee on National Resources. Parliamentary Paper No 495/ 1985. Canberra, Parliament of the Commonwealth of Australia.

Australia 1988. Antarctic rebuilding programme steering committee meeting, Hobart, Tasmania, 31 August. Hobart, Australian Construction Services.

Bates, G. 1983. Environmental law in Australia. Melbourne, Butterworths.

Beanlands, G. E. and Duinker, P. N. 1983. An ecological framework for environmental impact assessment in Canada. Halifax, institute for Resource and Environmental Studies, Dalhousie University.

Benninghoff, W.S. and Bonner, W. N. 1985. Man's impact on the Antarctic environment: a procedure for evaluating impacts from scientific and logistic activities. Cambridge, Scientific Committee on Antarctic Research.

Bonner, W. N. 1984. Conservation and the Antarctic. In: Laws, R. M. (editor). Antarctic ecology. London, Academic Press. Vol. 2: 821-40.

Buckley, R. 1988. Critical problems in environmental planning and management. Environmental and Planning Law Journal 5 (3): 206-25.

Chester, J. 1986. Going to extremes: Project Blizzard and Australia's Antarctic heritage. Sydney, Doubleday.

Headland, R. K. and Keage, P. L. 1985. Activities on the King George Island group, South Shetland Islands, Antarctica. Polar Record 22 (140): 475-84.

Holling, C. S. 1978. Adaptive environmental assessment and management. Brisbane, John Wiley (International Series on Applied Systems Analysis 3.)

Keage, P. L. 1986. Antarctic protected areas: future options. Occasional Paper 19. Centre for Environmental Studies, University of Tasmania, Hobart.

Keage, P. L. and Quilty, P. G. 1988. Future directions for Antarctic environmental studies. Maritime Studies 38 (January/February): 1-12.

Keys, H. 1987. Environmental impact assessment in New Zealand's Antarctic programme - where to from here? New Zealand Antarctic Record 8 (1): 9-16.

Kriwoken, L. K. and Keage, P. K. (1989). Antarctic environmental politics: protected areas. In: Handmer, J. and Birgin, R. (editors). Antarctica: policies and policy development. Canberra, Centre for Resource and Environmental Studies, Australian National University: Chapter 5: 31-48.

Law, P. 1983. Antarctic odyssey. Melbourne, Heinemann.

Lewis-Smith, R. 1986. Environmental impact and related matters in the Casey station area (Unpublished manuscript). Cambridge, British Antarctic Survey.

National Science Foundation. 1979. United States Antarctic Programme draft environmental impact statement. Washington, Division of Polar Programmes.

Sonntag, N. C., Everitt, R. R., Rattie, L. P.. Colnett, D. L., Wolf, C. P., Truett, J. C., Dorcey, A. H. J. and Holling, C.S. 1987. Cumulative effects assessment: a context for further research and development. Hull, Canadian Environmental Assessment Research Council. 